\title{
A new approach to endoscopic submucosal tunneling dissection: the "Speedboat-RS2" device
}

The "Speedboat-RS2" (Creo Medical Ltd., Wales, UK) is the first multimodality device incorporating bipolar radiofrequency (BRF) energy cutting, microwave coagulation (MWC), an integrated needle for submucosal injection, and a rotatable blade with a heat-insulated hull.

A 4-cm sessile proximal sigmoid lesion was examined using narrow-band imaging (NBI) and zoom magnification (Olympus Keymed; CF-HQ290ZL) ( $\mathbf{F i g . 1}$ a, b). A benign surface and vascular pattern (Kudo type IIIL/IV, NICE 2, JNET type 2a) was seen [1-3]. A complete resection was performed, with the patient under conscious sedation, taking 25 minutes (first mucosal incision to last submucosal cut) without recourse to any other accessory instruments.

Firstly, a narrow mucosal incision was made at the distal edge of the lesion, followed by progressively deeper submucosal dissection (BRF, cutting frequency $400 \mathrm{kHz}$, power setting $35 \mathrm{~W}$ ). The "Speedboat-RS2" was used to create a submucosal tunnel under the lesion [4, 5]. The novel design provided lateral and/ or forward cutting using the curved tip, flat edges of the blade. The 1:1 rotation of the Speedboat optimised submucosal tension, keeping the insulated hull parallel to the muscle layer. Repeated injections were administered by the retractable needle, after device rotation to allow direct visualisation of the needle exit point. A circumferential mucosal incision was completed to isolate the lesion. An "in-to-out" dissection technique was used to dissect the left- and right-bridged margins in a distal to proximal direction ( Video 1). The specimen was pinned out ( $\triangleright$ Fig. 2 a).

Haemostasis during the procedure was performed using MWC (frequency $5.8 \mathrm{GHz}$, power setting $10 \mathrm{~W})$. Smaller vessels $(<1 \mathrm{~mm})$ were pre-coagulated,

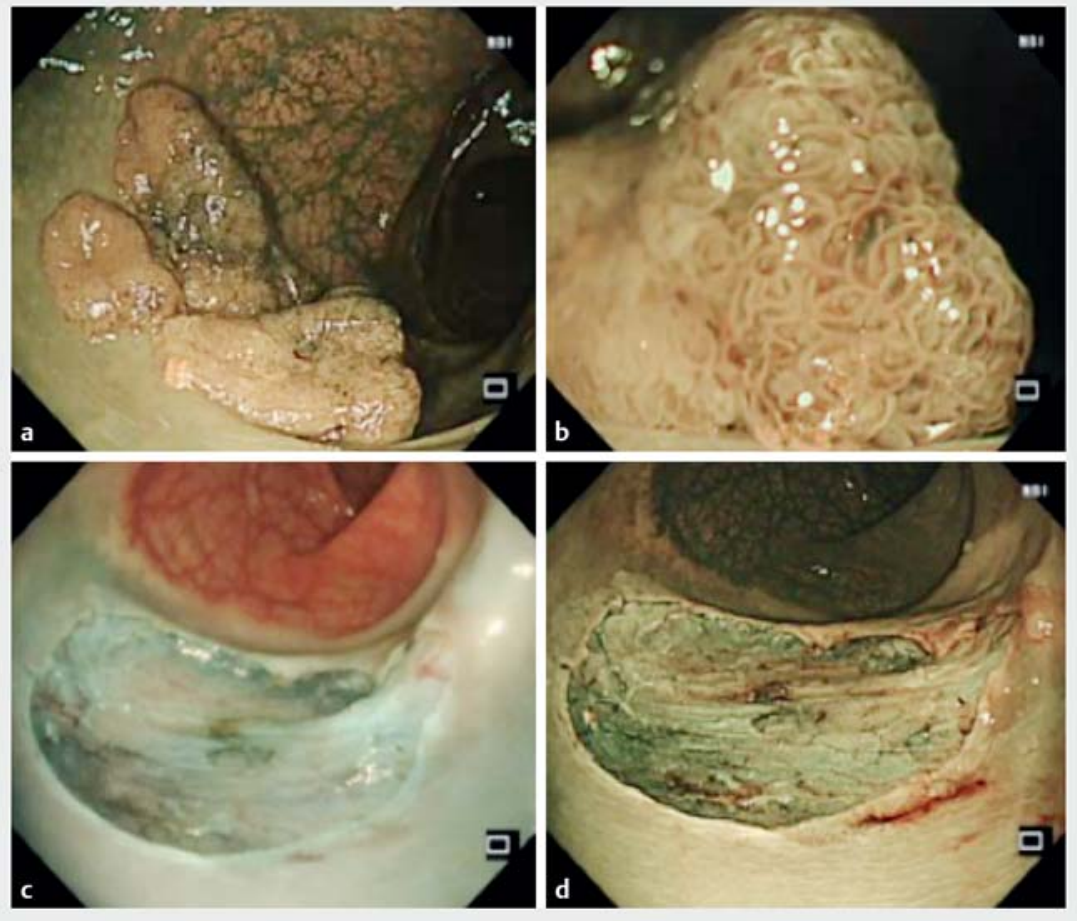

Fig. 1 Endoscopic images showing: a a 4-cm proximal sessile sigmoid colon lesion; b narrow-band imaging (NBI) and zoom magnification, revealing a lesion classified as Kudo IIIL/IV, NICE 2, JNET 2a; c white-light assessment of the post-dissection base, which is free of thermal injury and has clear margins; $\mathbf{d ~ N B I}$ assessment for the presence of residual tissue after dissection.

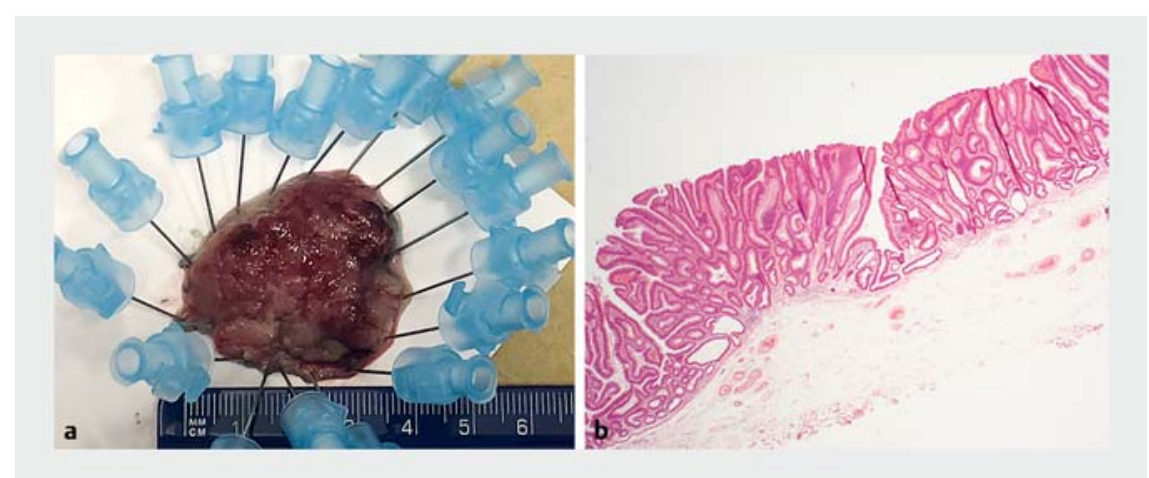

Fig. 2 Pathology of the resected specimen: a macroscopic appearance; $\mathbf{b}$ microscopic appearance, showing a tubular adenoma with low grade dysplasia, preserved entire mucosa and submucosal layers. 


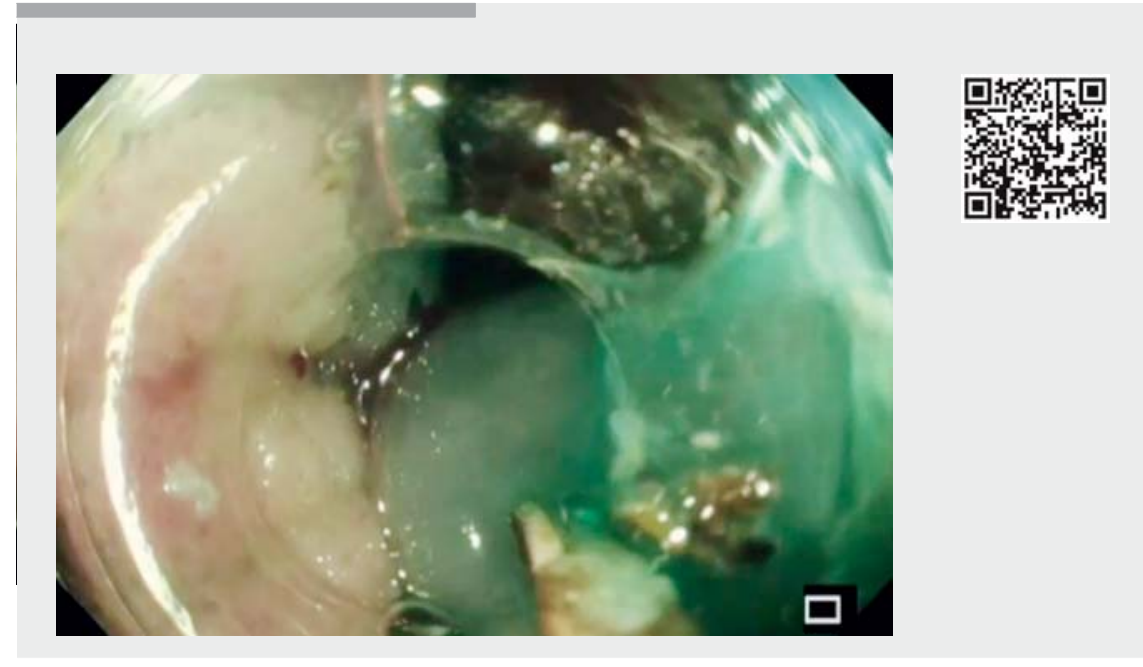

Video 1 The "Speedboat-RS2" device was used for an R0 dissection of a large sigmoid lesion using a submucosal dissection tunnelling technique.

producing a visual bubbling/blanching effect. When a vascular bundle was encountered, larger vessels $(>1 \mathrm{~mm})$ were pre-coagulated with microwave power for $6-10$ seconds. Any active bleeding was treated with tamponade using the device and further application of MWC ( $10 \mathrm{~W}$ for 10 seconds). The muscle in the resection base was free of thermal damage and the margins were uncharred ( Fig. 1 c, d; $\triangleright$ Video 1 ).

The patient made an uneventful recovery and was discharged 2 hours after the procedure. Histology confirmed an R0 resection of a tubular adenoma with low grade dysplasia. The submucosal layer was viable across the entire specimen ( Fig.2b).

Endoscopy_UCTN_Code_TTT_1AQ_2AD

\section{Acknowledgments}

We would like to acknowledge the Complex Polyp Team at East Kent Hospitals University Foundation NHS Trust for providing substantial senior nursing support from Mrs. Paula Morgan, Mrs. Rebecca Smith, and Mr. Jomell Ong.

\section{Competing interests}

Zacharias P. Tsiamoulos has a consulting agreement with Creo Medical Ltd. Christopher Hancock is CTO and founder of Creo Medical Ltd. Brian P. Saunders is on the advisory board and has a royalty agreement with Creo Medical Ltd. Joseph Sebastian and Nipin Bagla have no conflicts of interest to declare.

The authors

Zacharias P. Tsiamoulos ${ }^{1,2}$, Joseph Sebastian', Nipin Bagla ${ }^{1}$, Christopher Hancock ${ }^{3}$, Brian P. Saunders ${ }^{2}$

1 Queen Elizabeth the Queen Mother Hospital, East Kent Hospitals University Foundation NHS Trust, Margate, UK

2 Wolfson Unit for Endoscopy, St Mark's Hospital/Academic Institute, London, UK

3 Bangor University, Medical Microwave Systems Research Group, Bangor, UK

\section{Corresponding author}

Zacharias P. Tsiamoulos, MBBS, PhD Department of Gastroenterology, East Kent University Foundation Hospitals Trust, St Peter's Road, Margate, CT9 4AN, UK ztsiamoulos@nhs.net

\section{References}

[1] Kudo S, Tamura S, Nakajima T et al. Diagnosis of colorectal tumorous lesions by magnifying endoscopy. Gastrointest Endosc 1996; 44: $8-14$

[2] Hewett DG, Kaltenbach T, Sano Y et al. Validation of a simple classification system for endoscopic diagnosis of small colorectal polyps using narrow-band imaging. Gastroenterology 2012; 143: 599-607

[3] Sano Y, Tanaka S, Kudo SE et al. Narrowband imaging (NBI) magnifying endoscopic classification of colorectal tumors proposed by the Japan NBI Expert Team. Dig Endosc 2016; 28: 526-533

[4] Yamamoto H. Endoscopic submucosal dissection for colorectal tumors. In: Monkemuller K, Wilcox CM, Munoz-Navas M, eds. Interventional and Therapeutic Gastrointestinal Endoscopy (Frontiers of Gastrointestinal Research). Basel: Karger; 2010: 287 295

[5] Kobara H, Mori H, Chei L et al. The advantage of an endoscopic submucosal tunneling technique for rectal carcinoid tumors. Gut Liver 2017; 11: 735-737

\section{Bibliography}

DOI https://doi.org/10.1055/a-0875-3352

Published online: 12.4.2019

Endoscopy 2019; 51: E185-E186

(c) Georg Thieme Verlag KG

Stuttgart · New York

ISSN 0013-726X

\section{ENDOSCOPY E-VIDEOS \\ https://eref.thieme.de/e-videos}

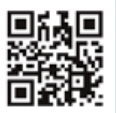

Endoscopy E-Videos is a free access online section, reporting on interesting cases and new

techniques in gastroenterological endoscopy. All papers include a high quality video and all contributions are freely accessible online.

This section has its own submission website at https://mc.manuscriptcentral.com/e-videos 